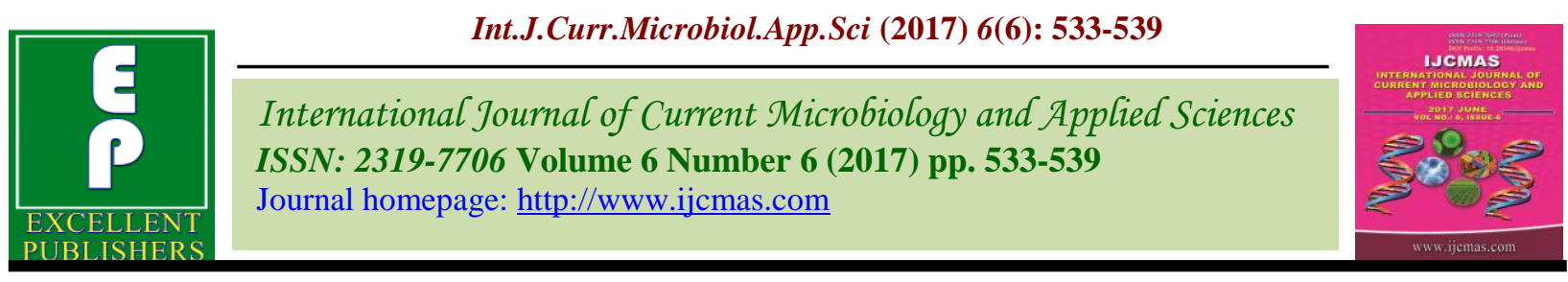

Review Article

https://doi.org/10.20546/ijcmas.2017.606.063

\title{
A Review on the Real Life Applications of Helium
}

\author{
Arvind Kumar Chhandak, Rekha Israni and A.V. Trivedi*
}

Bhagwant University Sikar Road Ajmer, 305004, Rajasthan, India

*Corresponding author

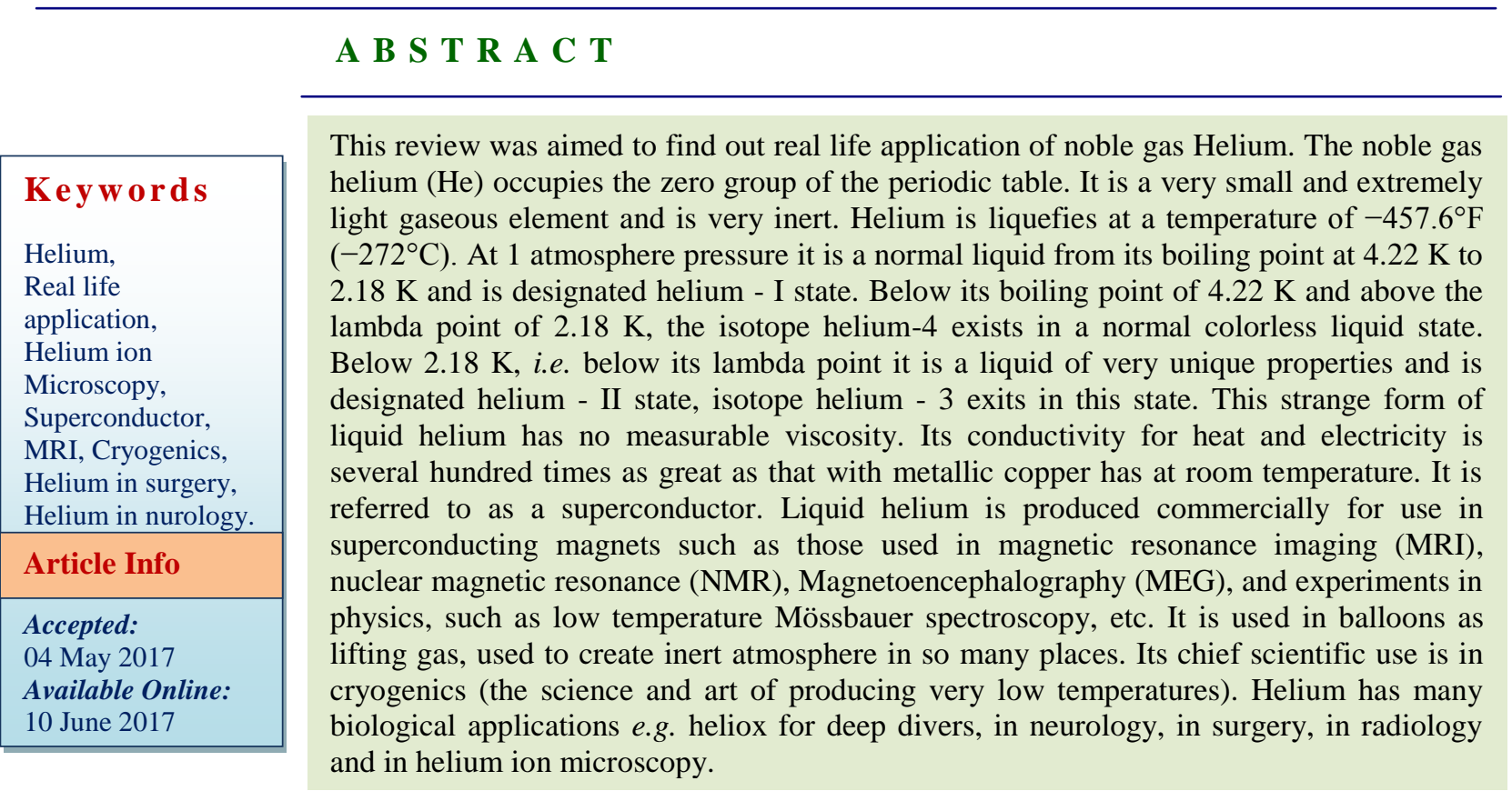

\section{Introduction}

The noble gas helium (He) occupies the last group of the periodic table, i.e. zero group. It is a very small and extremely light gaseous element. It is odorless, tasteless and least reactive of all elements. It is a non - metalic element and colorless gas at room temperature and pressure (Boris, 1994). Helium is an unusual and unique element among all elements known because it is the only element to have first been identified in the Solar System before it was discovered on Earth. Secondly helium has the lowest boiling point of any known substance which is $4.1 \mathrm{~K}$. In 1968 a French astronomer Pierre Janssen was first reported it when he analyse spectrum of sun light. Janssen called it "helium" after the Greek god Helios (Carlos, 2013; ShuenChe, 2005). Helium is the lightest noble gas (4 g/mol). The only gas with a lower density than helium is hydrogen. The use of hydrogen is more limited than helium because of its flammability in air mixtures. Helium (0.179 $\mathrm{g} / \mathrm{L})$ is $86 \%$ less dense than room air $(1.293$ $\mathrm{g} / \mathrm{L})$ and 8 times less dense than oxygen $(1.429 \mathrm{~g} / \mathrm{L})$. This unique property has been critical to its multiple applications (Harris, 2008). 


\section{The unique situation of helium}

Helium is remarkable, in that it only liquefies at a temperature of $-457.6^{\circ} \mathrm{F}\left(-272^{\circ} \mathrm{C}\right)$, just above absolute zero. Absolute zero is the temperature at which the motion of atoms or molecules comes to a virtual stop, but the motion of helium atoms never completely ceases. In order to liquefy it, in fact, even at those low temperatures, it must be subjected to pressures many times that exerted by Earth's atmosphere. Given these facts, it is difficult to extract helium from air. More often, it is obtained from natural gas wells, where it is present in relatively large concentrations between $1 \%$ and $7 \%$ of the natural gas (Emsley, 2011).

Liquid helium has some remarkable properties (Wang, 2013). At 1 atmosphere pressure it is a normal liquid from its boiling point at $4.22 \mathrm{~K}$ to $2.18 \mathrm{~K}$ and is designated helium - I state. Below its boiling point of $4.22 \mathrm{~K}$ and above the lambda point of $2.18 \mathrm{~K}$, the isotope helium-4 exists in a normal colorless liquid state (Clifford, 1968). Below $2.18 \mathrm{~K}$, i.e. below its lambda point it is a liquid of very unique properties and is designated helium - II state. Isotope helium 3 exixts in this state. Due to its high thermal conductivity, when it boils, it does not bubble but rather evaporates directly from its surface. Helium-3 also has a superfluid phase, but only at much lower temperatures; as a result, less is known about the properties of the isotope. This strange form of liquid helium has no measurable viscosity, and it cannot be confined in an open container because it creeps over the walls and flows down the outside (David, 2017). Its conductivity for heat and electricity is several hundred times as great as that with metallic copper has at room temperature. It is referred to as a superconductor (Clifford, 1968). liquid helium has been used as a cryogenic refrigerant, and liquid helium is produced commercially for use in superconducting magnets such as those used in magnetic resonance imaging (MRI), nuclear magnetic resonance (NMR), Magnetoencephalography (MEG), and in physics, such as low temperature Mössbauer spectroscopy (Rillo, et al., 2015).

\section{Real life application of helium}

Helium has so many applications in real life. These applications are mainly divided in two groups: 1. General applications and 2 . Biological applications

\section{General application of helium in real life}

Helium has the lowest boiling point of any known substance, i.e., $4.1 \mathrm{~K}$, therefore, its chief scientific use is in cryogenics (the science and art of producing very low temperatures). It is used to obtain the lowest temperatures required in lasers. Helium-neon gas lasers are used to scan barcodes in supermarket checkouts (Thomas and Robert, 1985). Helium is used in nuclear reactors as a cooling gas (Baxi, 1995) and used as a flowgas in liquid-gas chromatography (Hua-Li Zuo et al., 2013). It finds its application in airships and helium balloons. Helium balloons are used to check the weather of a particular region. Since the Hindenburg disaster in 1937 (Disaster, 1937) helium has replaced hydrogen as a lifting gas in blimps and balloons due to its lightness and incombustibility, despite an $8.6 \%$ decrease in buoyancy (Noble Gas, 2008). Secondly helium is preferred over hydrogen though hydrogen is cheaper, as helium is readily available. Hence due to safety issues helium is preferred in aircrafts. It is used by divers to dilute oxygen over nitrogen in the gas cylinders used by them as nitrogen can easily be dissolved in blood which results in a painful condition called as bends. The risk of helium causing bends is slightly lower than nitrogen (Robertson et al., 1969). For this reason a mixture of helium and oxygen is 
used in place of natural air for divers and others who work under high air pressure. Breathing compressed air causes considerable nitrogen to dissolve in the blood. When a diver is brought up rapidly and begins to breathe air at normal pressure again, much of the nitrogen that dissolved under high pressure comes out of solution, forming bubbles that also block the circulation of the blood (Hess, 2006).

In many applications, the noble gases are used to provide an inert atmosphere. Helium is used as the carrier gas medium in gas chromatography, as a filler gas for thermometers, and in devices for measuring radiation, such as the Geiger counter and the bubble chamber (Hwang, 2005). Helium and argon are both commonly used to shield welding arcs and the surrounding base metal from the atmosphere during welding and cutting, as well as in other metallurgical processes and in the production of silicon for the semiconductor industry (Häussinger, 2002). Because it is very unreactive, helium is used to provide an inert protective atmosphere for making fibre optics. Helium is also used to detect leaks, such as in car air-conditioning systems, and because it diffuses quickly it is used to inflate car airbags after impact.

Helium is used as a cooling medium for the Large Hadron Collider (LHC), and the superconducting magnets in MRI scanners (Michael, 2010) Helium is used for purposes that require some of its unique properties: its low density, low solubility, and high thermal conductivity. 7,000 tons, or $22 \%$, of the total helium used involves the cooling of superconducting magnets in medical magnetic resonance imaging (MRI) scanners and NMR spectrometers (Michael, 2010). It is also used to keep satellite instruments cool and is used to cool the liquid oxygen and hydrogen that powered the Apollo space vehicles (Lide, 2005).
Helium is used in industry to provide an inert atmosphere in electric arc welding of metals. An electric arc welding is a type of welding operation whereby the heat source used for welding is created when current flows between an electrode held by the welder and the work, which is connected to the opposite side of the electric source. In all electric arc processes, the electrode, the molten pool and the heat-affected metal parts must be protected from reaction (oxidation) with the surrounding air, hence a shielding gas must be introduced. Typical shielding gases consist of argon, helium or a mixture of the two (Emsley, 2001).

\section{Biological application of helium in real life}

Biological applications of helium are given below:

\section{Application of helium in heliox (80\%: 20\%/Helium: Oxygen)}

In 1926, Sayers and Yant found that heliumoxygen mixtures could be breathed by humans without discomfort, and by animals without demonstrable ill effects. Due to the lower solubility of helium compared with nitrogen, using a mixture of helium and oxygen (Heliox) rather than nitrogen and oxygen decreased the formation of nitrogen bubbles and therefore decompression illness in deep-sea divers (Sayers ans Yant, 1926). In 1934, Barach was first to propose using Heliox as a therapeutic gas (Barach, 1934). Since a helium/oxygen mixture (79/21) has a weight that is one-third compared with air, Barach proposed using this lighter gas to improve the flow of oxygen in patients with upper airway obstruction and asthma exacerbation (Barach, 1935; Barach, 1936). The high thermal conductivity of helium results in lower body temperature when the body is embedded in helium, which could result in decreased metabolism and decreased 
energy expenditure (Singer, 2007). Due to its reduced solubility, little helium is taken into cell membranes, and when helium is used to replace part of the breathing mixtures, such as in trimix or heliox, a decrease in the narcotic effect of the gas at depth is obtained (De Lange, 2009).

\section{Application of helium in neurology}

The lighter inert gas helium is not anesthetics at least up to the highest pressures that can be tolerated before the confounding effects of high-pressure neurological syndrome become pronounced (Koblin et al., 1998; Miller et al., 1967). In a study, Coburn et. al found that in an in vitro model of traumatic brain injury, treatment with helium at elevated pressures had neuroprotective effects (Coburn, 2008). In a different in vitro study of cultured neurons however, Rivzi et. al reported that normobaric helium was detrimental to neuron survival after hypoxia (Rizvi et al., 2009), and human tubular kidney cells (Rizvi et al., 2010).

In another study, rats treated with Helium below body temperature subjected to middle cerebral artery occlusion (MCAO) had decreased infarct size and improved neurological outcome. In rats treated with Helium at $33^{\circ} \mathrm{C}$, the neuroprotective effect of Helium was abolished. Remarkably, an in vitro study of Schwann cells isolated from sciatic nerves of 4-5 day old rats; researchers found that irradiating the cells with a Heliumneon laser caused proliferation of the cells in a dose dependent manner (Van and Bar, 1993). This application is promising in regards to neuron restoration post injury.

\section{Application of helium in surgery}

Laparoscopic surgery is now a widely performed in treating various abdominal diseases. The procedure requires distending the abdomen via insufflation with carbon dioxide gas to visualize abdominal structures and provide space for the manipulation of medical instruments. Carbon dioxide is absorbed by the peritoneum and alters physiologic parameters, which can complicate surgery: mainly changes to the heart and lungs (cardiopulmonary changes). Cheng et al., (2013) performed a meta-analysis of all the studies using other medical gases, nitrous oxide and helium, in creating the pneumoperitoneum required for performing abdominal laparoscopic surgery. Their results concluded that there were fewer cardiopulmonary changes with helium than with carbon dioxide (Cheng et al., 2013). Helium has been found to be a safe alternative as a $\mathrm{n}$ insufflant in high-risk patients undergoing laparoscopic renal surgery. Researchers cite that patients who benefit most are those with difficulty in clearing $\mathrm{CO}_{2}$ gas from their bloodstream, such as patients with comorbid conditions like COPD, congestive heart failure, chronic hypoxia from an intrapulmonary shunt, malignant hyperthermia, and chronic hypoxia from multiple pulmonary infarcts (Makarov, 2007). In general surgery, helium is being explored as a promising abdominal insufflant alternative to $\mathrm{CO}_{2}$ because in laboratory and clinical trials, helium has not produced the respiratory acidosis commonly associated with insufflation using $\mathrm{CO}_{2}$ (Naude and Bongard, 1995). Helium plasma technology has also found an application in abdominal and laparoscopic surgery. Helium plasma is being used in the thermal coagulation of tissues that clears the bleeding from the surgical field and enhances visualization of bleeding sites (Vargo, 2004).

\section{Application of helium in radiology}

Because of inherently low $1 \mathrm{H}$ abundance in the lungs, MRI of the lungs has been more challenging to adequately visualize than other 
body tissues. Furthermore, air-tissue interfaces in the lung create magnetic field distortions, which further diminishes the lung magnetic resonance $1 \mathrm{H}$ signal. Respiratory and cardiac motion further deteriorates pulmonary MRI quality. Inhaled, hyperpolarized helium (HP 3He) overcomes the low proton density in both normal and diseased lungs. Polarization of largely achieved using the spin exchange optical pumping method (SEOP) (Bouchiat et al., 1960; Frazier and Cheifetz, 2010).

Using the SEOP method, the helium gas is polarized overnight (12-14 hours) and inhaled by subjects from a bag mixed with medical nitrogen for immediate breath-hold imaging $(8-16 \mathrm{sec})$. The method is safe, requires no ionizing radiation dose, and can be repeatedly inhaled facilitating longitudinal (De lange et al., 2007; 2009), HP 3He MRI can provide additional information regarding lung oxygenation that was not possible with traditional high-resolution computed tomography (HRCT) or MRI.

\section{Application of helium in microscopy}

The helium ion microscope (HIM) has recently emerged as a novel tool for imaging and analysis with the capability of providing sub-nanometer resolution images of uncoated biologic tissues. Based on a bright ion source and small probe, the HIM offers advantages over the conventional field emission scanning electron microscope (Kim, 2013). The key features of the HIM include (1) high resolution (ca. $0.25 \mathrm{~nm}$ ), (2) great surface sensitivity, (3) great contrast, (4) large depthof-field, (5) efficient charge control, (6) reduced specimen damage, and (7) nanomachining capability. Due to the charge neutralization by flood electron beam, there is no need for conductive metal coating for the observation of insulating biological specimens by HIM (Matthew, 2013). There is growing evidence that the HIM has substantial potential for high-resolution imaging of uncoated insulating biological specimens at the nanoscale. Taking advantage of helium ion microscopy, Rice et. al were able to explore the epithelium of the rat kidney with unsurpassed image quality and detail (Rice, 2013).

\section{Acknowledgement}

Authors thanks Bhagwant University Sikar Road Ajmer, Rajasthan, India for providing facilities.

\section{References}

Barach, A.L. 1934. Use of helium as a new therapeutic gas. Proc Soc Exper Biol and Med. 32, 462 - 464.

Barach, A.L. 1935. The use of Helium in the treatment of Asthma and Obstructive lesions in the larynx and trachea. Ann Intern Med. 9(6): 739 - 765.

Barach, A.L. 1936. The Effects of Inhalation of Helium Mixed with Oxygen on the Mechanics of Respiration. J Clin Invest. 15(1): 47 - 61.

Bergman, D. 1949. Hydrodynamics and Third Sound in Thin He II Films. Physical Review. 188 (1): 370 - 384.

Baxi, C.B. 1995. Design, Fabrication and Testing of a Helium Cooled Module," Fusion Engineering and Design, 28, 22 26.

Boris, Z. 1994. Noble Gases. In: Encyclopedia of Inorganic Chemistry. 5, 2660 - 2680.

Bouchiat. M. Carver, T. and Varnum, C.1960. Nuclear polarization in $3 \mathrm{He}$ gas induced by optical pumping and dipolar exchange. Phys Rev Lett. 5, 373 - 375.

Carlos, J. Berganza and John, H. Zhang. 2013. The role of helium gas in medicine, Med Gas Res. 200 - 212. 
Cheng, Y. Lu. 2013. Gases for establishing pneumoperitoneum during laparoscopic abdominal surgery. Cochrane Database Syst Rev. 1, CD009569.

Clifford, A. Hampel, 1968. The Encyclopedia of the Chemical Elements. New York: Van Nostrand Reinhold. Pp. 256 - 268.

Coburn, M. Maze, M. and Franks N.P. 2008. The neuroprotective effects of xenon and helium in an in vitro model of traumatic brain injury. Crit Care Med. 36(2): 588 - 595.

David, K. 2017. Erratic helium prices create research havoc, helium. Physics Today. 70, 1 - 26.

De Lange, E.E., et al., 2007. The variability of regional airflow obstruction within the lungs of patients with asthma: assessment with hyperpolarized helium3 magnetic resonance imaging. $\mathbf{J}$ Allergy Clin Immunol. 119, 1072 1078.

De Lange, E.E. et al., 2009. Changes in regional airflow obstruction over time in the lungs of patients with asthma: evaluation with $3 \mathrm{He} \mathrm{MR}$ imaging. Radiology. 250:567 - 575.

Disaster Ascribed to Gas by Experts. 1937. The New York Times. Pp. 1.

Emsley, J. 2001. Nature's Building Blocks. Oxford University Press. Pp. 175 - 179

Emsley J. 2011. Nature's Building Blocks: An A-Z Guide to the Elements (2nd Edn) Oxford University Press, New York.

Frazier, M.D, and Cheifetz I.M. 2010 the Role of Heliox in Paediatric Respiratory Disease. Paediatr Respir Rev. 11(1): 46 $-53$.

Harris, P.D. and Barnes, R. 2008. The uses of helium and xenon in current clinical practice. Anesthesia. 63, 284 - 293.

Häussinger, P. et al., 2002. "Noble gases". Ullmann's Encyclopedia of Industrial Chemistry. Wiley.
Hess, D.R. 2006. The history and physics of Heliox. Respir Care. 51(6): 608 - 612.

Hua-Li Zuo, et.al. 2013. Preparative Gas Chromatography and Its Applications, Journal of Chromatographic Science. 1 12.

Hwang, Shuen-Chen, Lein, Robert D. and Morgan, Daniel A. 2005. "Noble Gases". Kirk Othmer Encyclopedia of Chemical Technology. Wiley. Pp. 343 383.

Rizvi, j. N. et al., 2009. Neuroprotection (and lack of neuroprotection) afforded by a series of noble gases in an in vitro model of neuronal injury. Neurosci Lett. 460(3): 232 - 236.

Kim, Ki Woo. 2013. Biological Applications of Helium Ion Microscopy; Applied Microscopy. 43, 9.

Koblin, D.D. et al., 1998. Minimum alveolar concentrations of noble gases, nitrogen, and sulfur hexafluoride in rats: Helium and neon as nonimmobilizers (nonanesthetics) Anesth Analg. 87, 419 $-424$.

Lide, D. R., ed. 2005. CRC Handbook of Chemistry and Physics (86th Ed.). CRC Press. Boca Raton. (FL)

Makarov, D.V. et al., 2007. Physiologic Changes during Helium Insufflation in High-Risk Patients during Laparoscopic Renal Procedures. Urology. 70(1): 35 37.

Matthew, S. 2013. Helium Ion Microscopy (HIM) for the imaging of biological samples at sub-nanometer resolution. Scientific Reports. 3, Article number: 3514.

Michael, B. 2010. Helium sell-off risks future supply, Physics World.

Miller, K.W., Paton, W.D., Streett, W.B. and Smith, E.B. 1967. Animals at very high pressures of helium and neon. Science. 157, 97 - 98]

Naude, G.P., Bongard, F.S. 1995. Helium Insufflation in Laparoscopic Surgery. 
Endosc Surg Allied Technology. 3(4): 183 - 186.

Noble Gas.2008. Encyclopædia Britannica.

Rice, W.L. et al., 2013. High Resolution Helium Ion Scanning Microscopy of the Rat Kidney. PLoS One. 8 (3): e57051.

Rizvi, M. Jawad, et al., 2010. Effect of Noble Gases on oxygen and glucose deprived injury in human tubular kidney cells. Exp Biol Med.235 (7): 886 - 891.

Rillo, C. et al., 2015. Enhancement of the Liquefaction Rate in Small-Scale Helium Liquefiers Working Near and Above the Critical Point. Phys. Rev. Applied. 3, 051001- 051009

Robertson, I., Hemp, J. and Nyman, R. 1969. Helium Dive into the Silent Pool. Triton. 1 - 45

Sayers, R.R. and Yant, W.P. 1926. The Value of Helium-Oxygen Atmosphere in Diving and Caisson Operations. Anesth Analg. 5(3): 127 - 138.

Shuen-Chen, H., Robert D. Lein and Daniel A. Morgan. 2005. "Noble Gases". Kirk
Othmer Encyclopedia of Chemical Technology. Wiley. Pp. 343 - 383.

Singer, D. 2007. Why 37 degrees C? Evolutionary fundamentals of thermoregulation. Anesthetist. 56, 899 906.

Thomas, J. Kane and Robert, L. Byer. 1985. Monolithic, unidirectional single-mode Nd:YAG ring laser. Optics Letters 10(2): $65-67$

Van, Breugel H.H., Bar, P.R. 1993. He-Ne laser irradiation affects proliferation of cultured rat Schwann cells in a dosedependent manner. J Neurocytol. 22(3): 185 - 190.

Vargo, J.J. 2004. Clinical applications of argon plasma coagulator. Gastrointest Endosc. 59, 81 - 88.

Wang, B. and Gan, Z.H. 2013. A critical review of liquid helium temperature high frequency pulse tube cryocoolers for space applications. In Progress in Aerospace Sciences. 61, 43 - 70

\section{How to cite this article:}

Arvind Kumar Chhandak, Rekha Israni and Trivedi, A.V. 2017. A Review on the Real Life Applications of Helium. Int.J.Curr.Microbiol.App.Sci. 6(6): 533-539. doi: https://doi.org/10.20546/ijcmas.2017.606.063 